Fisheries Research

March 2019, Volume 211 Pages 27-31

https://doi.org/10.1016/i.fishres.2018.10.025

https://archimer.ifremer.fr/doc/00466/57818/

\title{
Tagging Atlantic bluefin tuna from a farming cage: An attempt to reduce handling times for large scale deployments
}

\author{
Rouyer Tristan ${ }^{1,{ }^{*}}$, Bonhommeau Sylvain ${ }^{2}$, Giordano Nicolas ${ }^{3}$, Ellul Saviour ${ }^{4}$, Ellul Giovanni ${ }^{4}$, \\ Deguara Simeon ${ }^{5}$, Wendling Bertrand ${ }^{6}$, Belhaj Mohamed Moez ${ }^{7}$, Kerzerho Vincent ${ }^{7,8}$, \\ Bernard Serge ${ }^{7,8}$
}

${ }^{1}$ MARBEC Univ Montpellier, CNRS, Ifremer, IRD, Sète, France

2 IFREMER DOI, rue Jean Bertho, 97822, Le Port, La Réunion, France

${ }^{3}$ Armement « Saint Sophie François II \& III », SARL SSF, 15, Quai d'Alger, 34200, Sète, France

${ }_{5}^{4}$ MFF Ltd., Hangar, Triq it - Trunciera, Marsaxlokk, MXK 1522, Malta

${ }^{5}$ AquaBioTech Group, Central Complex Naggar Street - Targa Gap, Mosta, MST 1761, Malta

${ }^{6}$ SATHOAN, 28, promenade J.B. Marty, 34200, Sète, France

${ }^{7}$ LIRMM, 161 Rue Ada, 34095, Montpellier, France

* Corresponding author : Tristan Rouyer, email address : tristan.rouyer@ifremer.fr

\begin{abstract}
:
Our knowledge on the biology and ecology of marine species have improved greatly through the use of archival tags by enabling the collection on information from individual in the wild. This is specifically true for large pelagic species such as the Atlantic Bluefin tuna (ABFT, Thunnus thynnus) where, for the first time, it has been possible to confirm through fisheries-independent data, migration patterns, reproductive and feeding behaviours and habitat use. However, large-scale tagging experiments that would enable researchers to tackle group behaviour are difficult to set up. On the one hand, the impact of the actual tagging operation should be as minimal as possible to avoid any change in behaviour of the fish which could influence tag data analyses. On the other hand, large scale tagging experiments require handling a large number of animals in a relatively short period of time. In the present manuscript, a methodology for tagging several large ABFT with satellite tags was tested with ABFT caught from a cage of a Maltese farm. The total time of the operation, from the moment fish were caught by handline to release back to the sea lasted an average of $10 \mathrm{~min}$ for the 3 fish tagged. The handling of the fish on the deck lasted less than $2 \mathrm{~min}$. This methodology proved successful at tagging several large $(158-182 \mathrm{~cm})$ fishes in a very short time, while ensuring the best conditions for the fish during tagging and subsequent release. This procedure requires substantial logistical preparation and an experienced crew team but, by reducing the time required for the operation, opens up the possibility of large scale tagging activities of large fish held in cages or caught by purse seiners.
\end{abstract}




\section{Highlights}

- A methodology was tested to allow for large scale tag deployment on bluefin tuna. Three large tunas were tagged from a fattening cage in about ten minutes each. No mortality was observed as the tagging conditions, on deck, were optimal. Using handlines to catch the fish from within the cage proved successful. The behaviour of fish held in captivity and released into the wild could be observed.

Keywords : Large Atlantic bluefin tuna, Electronic tagging, Release, Farming cage 


\section{INTRODUCTION}

42

43 Tagging using electronic tags is an important tool used to understand the life cycle of many

44 fishes. Since the 1990s, the use of these tags has substantially improved our knowledge of the 45 biology and ecology of numerous marine species (Block et al., 2011; Hussey et al., 2015). This 46 is specially true for large migratory pelagics species such as the Atlantic Bluefin tuna (ABFT, 47 Thunnus thynnus), a commercially important top predator (De Metrio et al., 2002; Block et al., 48 2005; De Metrio et al., 2005; Walli et al., 2009; Fromentin and Lopuszanski, 2014).

50 This species is managed by the International Commission for the Conservation of Atlantic Tunas 51 (ICCAT) as two stocks (eastern and western stocks), with mixing occurring in foraging areas.

52 The eastern stock groups the East Atlantic and the Mediterranean Sea and is the largest stock.

53 ABFT is capable of movements across long distances and can move from one stock region to 54 another (Rooker et al., 2007). The complexity of these movements, and in particular in 55 relationship to its spawning areas, is far from being resolved (Richardson et al., 2016). 56 Therefore, quantifying these movements is currently still an important challenge to improve the 57 understanding of the species' ecology, but also for its management (e.g. implementation of the 58 Management Strategy Evaluation, MSE). However, quantifying these movements is not an easy task. ABFT shows a great amount of inter-individual variation in terms of movements, which also 60 greatly differ from one year to another and even at larger time scales. For example, recent years

61 have seen large individuals of ABFT moving to higher latitudes, to feed on mackerel and 62 herring(MacKenzie et al., 2014), after several decades of disappearance in these areas 63 (Fromentin and Powers, 2005; Fromentin, 2009). ABFT also occurred for a few decades in 64 Brazilian waters before disappearing, the so-called "Brazilian episode" (Fromentin et al., 2014). 65 
Quantifying such movements would ideally require the deployment of numerous electronic tags each year, so that enough information could be collected to meaningfully assess the number of individuals moving from one area to another while accounting for inter-individual variability. To facilitate the assessment of the true variability of migratory behaviour between individuals, optimally, there should be equal tagging conditions (location, size, day of the year, etc.) yearly. Such conditions could be controlled if several individuals from the same school could be tagged. However, such a large scale operation is not easily arranged because a large number of fish

73 have to be tagged in a short amount of time, and appropriately handling ABFT is not 74 straightforward. Tagging ABFT for long-term deployments is better achieved by placing the fish 75 on the deck, as the tag can then be deployed with enough precision to increase the probability of long retention times that can regularly last more than 4 months (Fromentin and Lopuszanski,

77 2014). The operation consists of inserting the anchor of the tag through the bones under the second dorsal fin (pterygiophores, Fig. 1), which is easier to achieve onto a deck than under water (Cort et al., 2010; Tensek et al., 2017). However, the large size and weight that ABFT can reach makes hauling up the live fish onto the deck rather difficult, especially since the process has to be as quick as possible to avoid stress and mortality and reduce the impact on the animal 82 inluding injury and subsequent behaviour.

In the Mediterranean Sea, the largest amount of catch is made by the purse seiners fishery during the spawning season (fishing season). The purse seiner fleet has access to a substantial amount of the total allowable catch to the eastern stock fishing fleets. Nowadays the fleet operates in the Balearic Islands, in the Tunisian and Maltese Waters, in the South-East of the

88 Tyrrhenian sea and in the southern coast of Turkey. The vast majority of the catch, consisting of 89 mature fish, is transferred into cages to fatten the fish. These purse seine catches represent a 90 very interesting opportunity for large-scale tagging operations as the fish, usually spawners and 
91 hence large (50 to $>500 \mathrm{~kg}$ ), are caught in the hundreds. However, as a first attempt at tagging

92 several tunas in one go, using fish already housed in a cage is convenient. It allows to have

93 access to a large number of fish that are used to being held in a confined space, without having

94 to deal with the stress and variability inherent to the fishing operations with a restricted time

95 frame and unpredictable meteorological conditions. Tagging fish from a cage also opens up the

96 possibility to study the behaviour of ABFT that are released every year from the cages as part of

97 the over-catch procedures (ICCAT Rec. 17-07).

98

99 Nonetheless, getting ABFT out of a cage for large scale tagging purposes requires a quick and 100 efficient methodology so that they can be tagged appropriately and returned to their natural 101 environment in good condition. Techniques employed so far have involved isolating individuals 102 in a confined space and catching them directly through the use of divers, which is not optimal for 103 ABFT as the fish can get easily stressed and exhausted during the operation and lead to higher

104 risks of mortalities. Tagging using harpoons or spearfishing techniques are also used, but they

105 suffer from the major problem of lacking accuracy for inserting the main anchor, which is an

106 important aspect for electronic tags to ensure a greater probability of a long retention times

107 (Chaprales et al., 1998; Aranda et al., 2013).

108

109 In the present manuscript, we present an operation carried out on a ABFT farming cage in

110 Malta. The objective of the operation was (i) to show that it is possible to use a handline to fish

111 out relatively large tunas from a confined area and (ii) to show that such a technique allows for

112 quick deployments of tags on fish and release of these fish in good condition.

113 


\section{2.1.Tagging location}

119 Three ABFT were made available by the company Malta Fish Farming (MFF Ltd) for the tagging

120 operation. The fishes had been caught during the 2016 purse-seine fishing season and were

121 housed in a 50m diameter cage, off the harbour of Marsaxlokk. These fish were caught from

122 inside the cage using a handline with large hooks used by local longline fishermen, baited with

123 frozen mackerel and herring. The operation took place in the early morning so that the tunas in

124 the cage would be as calm as possible and to maximize the probability that the fish would take

125 the bait. The day was chosen so that the meteorological conditions were optimal, flat sea and 126 sunny clear sky, to facilitate the operation.

2.2.Personnel and equipment

131 The barge used during the operation was equipped with a crane that was used to haul the fish 132 out of the cage and back into the water after tagging. The tagging team consisted of three 133 scientists to handle the fish and tag it, two fishermen to catch the fish, three divers to move the

134 fish into a stretcher, one crane operator to lift the stretcher from the cage onto the deck and 135 back into the open water, plus the captain of the vessel. The barge had a large open deck on 136 which a $5 \mathrm{~cm}$ thick mattress was laid to avoid hurting the lateral line of the fish. The stretcher

137 had specifically been designed for the operation and made of a material used for catamaran 138 trampolines (Fig. 2). This material is smooth and does not remove the mucus of the fish while 
139 letting the water flow through. The mouth of the stretcher was kept opened in the water using a

140 chain, whereas the other end of the stretcher was kept closed with a rope that was removed

141 before the fish was released back into the water. The stretcher was attached to the crane at a

142 slight angle so that the entrance of the stretcher would be higher than its exit to prevent the fish

143 from falling while the crane was being operated to haul it out of the cage.

146 2.3.Tagging

148 Three pop-up tags (MiniPATs, Wildlife Computers) were set-up to pop-off after 90, 180 and 360

149 days, respectively. The tags were rigged with metal $12 \mathrm{~cm}$ long tethers and Domeier anchors.

150 The main anchor was inserted at the base of the second dorsal fin, so that the Domeier anchor

151 would go through the pterygiophores and get tangled in them (Cort et al., 2010). Doing so

152 increases the probability of long-term retention of the tag. In addition, a second anchor was

153 used to limit the lateral movements of the tag on the body of the tagged individuals (Fromentin

154 and Lopuszanski, 2014). This limits the probability of bruises on the sides of the fish. Both

155 anchors and the material used for the tagging were treated with chlorhexidine, a disinfectant 156 and antiseptic.

158 After throwing some bait into the cage, a handline with a baited hook was thrown into the cage, 159 left sinking a few seconds and towed back to the boat (Fig. 2a). Once a tuna took the bait the 160 fish was manoeuvered towards the surface by the fishermen as quickly as possible to avoid the 161 exhaustion of the fish and consequently a lower probability of survival. However the strength of 162 the fish limited the speed at which the fishermen could get it close to the barge. Once the fish 163 reached the surface, it was placed in the stretcher by the divers that were waiting around the 
164 cage (Fig. 2b). The stretcher was then lifted onto the mattress (Fig. 2c,d) on the barge. The rope

165 of the exit of the stretcher was undone, the eyes of the fish were then immediately covered to

166 calm the fish down and a water pipe was inserted into its mouth to ensure a continuous

167 provision of oxygen (Fig. 2e,f). The total fork length of the fish was measured and the fish was

168 tagged, while the hook was removed from its mouth (Fig. $2 \mathrm{~g}, \mathrm{~h}$ ). The fish was then immediately

169 released into the wild (Fig. 2i-n).

170 


\subsection{Tagging operation}

175

176 Three ABFT of 170,158 and $182 \mathrm{~cm}$ straight fork length, were caught successively on May the $1774^{\text {th }}$ 2017. The fish were caught with handlines and hauled onto the deck of the barge in less than 17810 minutes each. The time on deck including covering the eye, intubation, removal of the hook, 179 measurement, tagging and getting the fish back into the water was less than two minutes for 180 each fish. The total time of the operation from start to finish was less than 40 minutes.

\subsection{Retention times and movements}

185 The tags did not remain attached as long as expected. The first fish was caught after only a few 186 weeks by a fisherman on June $1^{\text {st }} 2017$ (Tag 170333, programmed for 90 days, 27 days at 187 large). The second tag was released on the $10^{\text {th }}$ of June 2017 (Tag 170334, programmed for 188180 days, 37 days at large) and the third tag (Tag 170332, programmed for 360 days) was 189 released on June $23^{\text {rd }} 2017$ (50 days at large). The geolocation of the fish was obtained by 190 using the GPE3 state-space model algorithm from Wildlife Computers. The track of the first fish

191 (Fig. 3) showed movements in the south of Malta, with the fish remaining in the general vicinity 192 of the island. The track of the second fish displayed a comparable track to the first until the fish 193 got caught by a fisherman. The tag then moved to the harbour of Tebulbah in Tunisia. The track 194 of the third fish was quite different from these two tracks. It displayed eastwards movements 195 across the Ionian sea towards the western Greek coast. The three fish spent a large amount of 
196 time in the upper layer $(0-20 \mathrm{~m})$ of the water column, where up to $83 \%$ of occurrences were

197 recorded (Table 1 ). This upper layer was characterized by relatively warm waters, above $20^{\circ} \mathrm{C}$

198 during this period (Fig. 3).

199

200

201 
204 The methodology that was used for the tagging operation allowed to tag three large fish on the

205 deck of the barge, in a relatively short amount of time, about 10 min each, and without suffering

206 any mortality. This methodology could thus allow large scale tag deployments with the fish being

207 tagged onto the deck. Large scale deployments are an important perspective to improve our

208 knowledge on ABFT, for instant about group behaviour, but also to feed the stock assessment

209 with relevant information. For instance, tagging data is used to obtain migration probabilities

210 between different areas for the stock assessment model or for testing management procedures

211 for ABFT (Powers and Porch, 2003; Carruthers, 2016).

212

213 Attempts to tag several fish from the same school have been made through several programs

214 from the northwest Atlantic (Lutcavage et al., 1999; Block et al., 2001). Attempts in the

215 Mediterranean Sea, mainly through the Atlantic-Wide Research Programme on Bluefin Tuna

216 (GBYP), had a large focus on smaller tunas (Tensek et al., 2017). Large tunas were also tagged

217 from traps, but the technique rarely involved getting the fish on the deck, but rather using poles

218 or underwater spearguns to tag the fish. Using cages has proved successfull for tagging large

219 amount of fish, but mainly involved small fishes (Tičina et al., 2003, 2004).

220

221 Apart from the methodological aspects and the perspectives of large scale deployments opened

222 by this operation, tagging fish from cages can bring insights into the behaviour of ABFT held in

223 cages for a period of time and then released into the wild. This is important as the quantity of

224 ABFT that are caught by the purse seine fishery can exceed the quota, which leads to the

225 release of excess fish at the end of the fishing season. Observing the behaviour of the fish

226 released to assess whether they return to the behaviour shown by wild fish is also of interest. 
227 The present case does not precisely fall into this category as the fish that were tagged had been

228 housed in a fattening cage for almost one year. However, it was interesting to note that two of

229 the fishes tagged during the operation remained in the vicinity of Malta during the spawning

230 season in an area known to be visited by ABFT during this period of the year. More surprisingly,

231 the third fish moved quickly towards the western Greek coast in the lonian sea, which is not part

232 of the areas commonly described through tagging studies at this period of the year.

233

234 The retention times were not as long as was expected with this technique and did not allow to

235 go deeper in the analysis of the tracks. A fish was caught in Tunisian waters shortly after having

236 been tagged, which resulted in a short retention time (27 days). The two other tags remained 37

237 and 50 days at large, which is equivalent to the retention times obtained by $30 \%$ of the tags

238 during the GBYP operations and above the retention time obtained by $40 \%$ of the tags during

239 the same operations (Tensek et al., 2017). The reason for these premature releases remained

240 unresolved as the tag did not show any sign of failure. Explanations could be related to a bad

241 attachment of the tag to the fish or to a failure of the leader, or even to the fish being caught by

242 a fisherman (Musyl et al. 2011). Low reporting rates did not affect the present study, but it has

243 been identified as an important limiting factor for many other studies (Musyl et al. 2011). As this

244 was the first time such an operation was conducted, large improvements can be expected for

245 future deployments.

246 


\section{ACKNOWLEDGEMENTS}

248 This research was part of the MERLIN-POPSTAR project funded by Ifremer. We thank our 249 colleagues from Ifremer/REM/RDT and RBE, CNRS, UM and IRD who provided insight and 250 expertise that greatly assisted the research. We thank MFF Ltd for letting us use their facilities 251 and the crew for their great skills and assistance. 
Aranda, G., Abascal, F. J., Varela, J. L., and Medina, A. 2013. Spawning Behaviour and PostSpawning Migration Patterns of Atlantic Bluefin Tuna (Thunnus thynnus) Ascertained from Satellite Archival Tags. PLOS ONE, 8: e76445.

Block, B. A., Dewar, H., Blackwell, S. B., Williams, T. D., Prince, E. D., Farwell, C. J., Boustany, A., et al., 2001. Migratory Movements, Depth Preferences, and Thermal Biology of Atlantic Bluefin Tuna. Science, 293, 1310-1314.

Block, B. A., Teo, S. L. H., Walli, A., Boustany, A., Stokesbury, M. J. W., Farwell, C. J., Weng, K. C., et al., 2005. Electronic tagging and population structure of Atlantic bluefin tuna. Nature, 434, 1121-1127.

Block, B. A., Jonsen, I. D., Jorgensen, S. J., Winship, A. J., Shaffer, S. A., Bograd, S. J., Hazen, E. L., et al., 2011. Tracking apex marine predator movements in a dynamic ocean. Nature, 475, 86-90.

Carruthers, T., 2016. Short-term contract for modelling approaches: support to BFT assessment (GBYP 06/2017) of the Atlantic-Wide Research Programme on Bluefin tuna (ICCATGBYP - Phase 7): 13.

Chaprales, W., Lutcavage, M., Brill, R., Chase, B., and Skomal, G. 1998. Harpoon Method for Attaching Ultrasonic and 'Popup' Satellite Tags to Giant Bluefin Tuna and Large Palegic Fishes. Marine Technology Society. Marine Technology Society Journal; Washington, 32: 104.

Cort, J. L., Abascal, F., Belda, E., Bello, G., Deflorio, M., Estruch, V., Godoy, D., et al., 2010. Tagging manual for the Atlantic-Wide Research Programme for Bluefin Tuna (ICCATGBYP). Introduction: 42pp.

De Metrio, G., P. Arnold, G., Block, B., M. de la Serna, J., Deflorio, M., Cataldo, M., Yannopoulos, C., et al., 2002. Behaviour of post-spawning Atlantic bluefin tuna tagged 
with pop-up satellite tags in the Mediterranean and Eastern Atlantic. Collective Volumes of Scientific Papers ICCAT, 54, 415-424.

De Metrio, G., Arnold, G.P., de la Serna, J.M., B.A. Block, Megalofonou, P., Lutcavage, M., Oray, I., and Deflorio, M., 2005. Movements of bluefin tuna (Thunnus thynnus L.) tagged in the Mediterranean Sea with pop-up satellite tags. Collective Volumes of Scientific Papers ICCAT, 58(4), 1337-1340.

Fromentin, J. M., and Powers, J. E., 2005. Atlantic bluefin tuna: population dynamics, ecology, fisheries and management. Fish and Fisheries, 6, 281-306.

Fromentin, J.-M., 2009. Lessons from the past: investigating historical data from bluefin tuna fisheries. Fish and Fisheries, 10, 197-216.

Fromentin, J.-M., Reygondeau, G., Bonhommeau, S., and Beaugrand, G., 2014. Oceanographic changes and exploitation drive the spatio-temporal dynamics of Atlantic bluefin tuna (Thunnus thynnus). Fisheries Oceanography, 23(2), 147-156.

Fromentin, J.-M., and Lopuszanski, D., 2014. Migration, residency, and homing of bluefin tuna in the western Mediterranean Sea. ICES Journal of Marine Science, 71(3), 510-518.

Hussey, N. E., Kessel, S. T., Aarestrup, K., Cooke, S. J., Cowley, P. D., Fisk, A. T., Harcourt, R. G., et al., 2015. Aquatic animal telemetry: A panoramic window into the underwater world. Science, 348, 1255642.

Lutcavage, M. E., Brill, R. W., Skomal, G. B., Chase, B. C., and Howey, P. W., 1999. Results of pop-up satellite tagging of spawning size class fish in the Gulf of Maine: do North Atlantic bluefin tuna spawn in the mid-Atlantic? Canadian Journal of Fisheries and Aquatic Sciences, 56, 173-177.

MacKenzie, B. R., Payne, M. R., Boje, J., Høyer, J. L., and Siegstad, H., 2014. A cascade of warming impacts brings bluefin tuna to Greenland waters. Global Change Biology, 20, 2484-2491. 
Musyl, M. K., Domeier, M. L., Nasby-Lucas, N., Brill, R. W., McNaughton, L. M., Swimmer, J. Y., Lutcavage, M. S., et al. 2011. Performance of pop-up satellite archival tags. Marine Ecology Progress Series, 433: 1-28.

Powers, J. E., and Porch, C. E., 2003. Approaches to incorporating mixing and movement of Atlantic bluefin tuna into management and assessment. ICES CM2003/V:25.

Richardson, D. E., Marancik, K. E., Guyon, J. R., Lutcavage, M. E., Galuardi, B., Lam, C. H., Walsh, H. J., et al., 2016. Discovery of a spawning ground reveals diverse migration strategies in Atlantic bluefin tuna (Thunnus thynnus). Proceedings of the National Academy of Sciences, 113(12), 3299-3304.

Rooker, J. R., Bremer, J. R. A., Block, B. A., Dewar, H., Metrio, G. de, Corriero, A., Kraus, R. T., et al., 2007. Life History and Stock Structure of Atlantic Bluefin Tuna (Thunnus thynnus). Reviews in Fisheries Science, 15, 265-310.

Tensek, S., Natale, A. D., and García, A. P., 2017. ICCAT GBYP PSAT tagging: the first five years. Collective Volumes of Scientific Papers ICCAT, 73(6), 2058-2073.

Tičina, V., Grubišić, L., Katavic, I., Jeftimijades, I., and Franicevic, V., 2003. Tagging of small bluefin tuna in the growth-out floating cage. Report of the research activities on tuna farming in the adriatic sea during 2002.

Tičina, V., Grubišić, L., and Katavić, I., 2004. Sampling and tagging of live bluefin tuna in growth-out floating cages. Aquaculture Research, 35, 307-310.

Walli, A., Teo, S. L. H., Boustany, A., Farwell, C. J., Williams, T., Dewar, H., Prince, E., et al., 2009. Seasonal Movements, Aggregations and Diving Behavior of Atlantic Bluefin Tuna (Thunnus thynnus) Revealed with Archival Tags. PLOS ONE, 4, e6151. 
254 TABLE

255

256 Table 1: Percentage of occurences at different depth bins for each tag

Depth Range MiniPAT 170332 MiniPAT 170333 MiniPAT 170334

5-0

10-5

20-10

30-20

40-30

50-40

100-50

200-100

500-200

800-500
25.9

27.4

20.3

8.9

1.6

1.2

6.4

5.7

2.5

0
25.6

6.2

18.8

11

8.1

6.7

17.1

5.4

1

0
51.1

21.3

11.2

2.9

1.8

1.6

6

3.2

0.9

0.1 

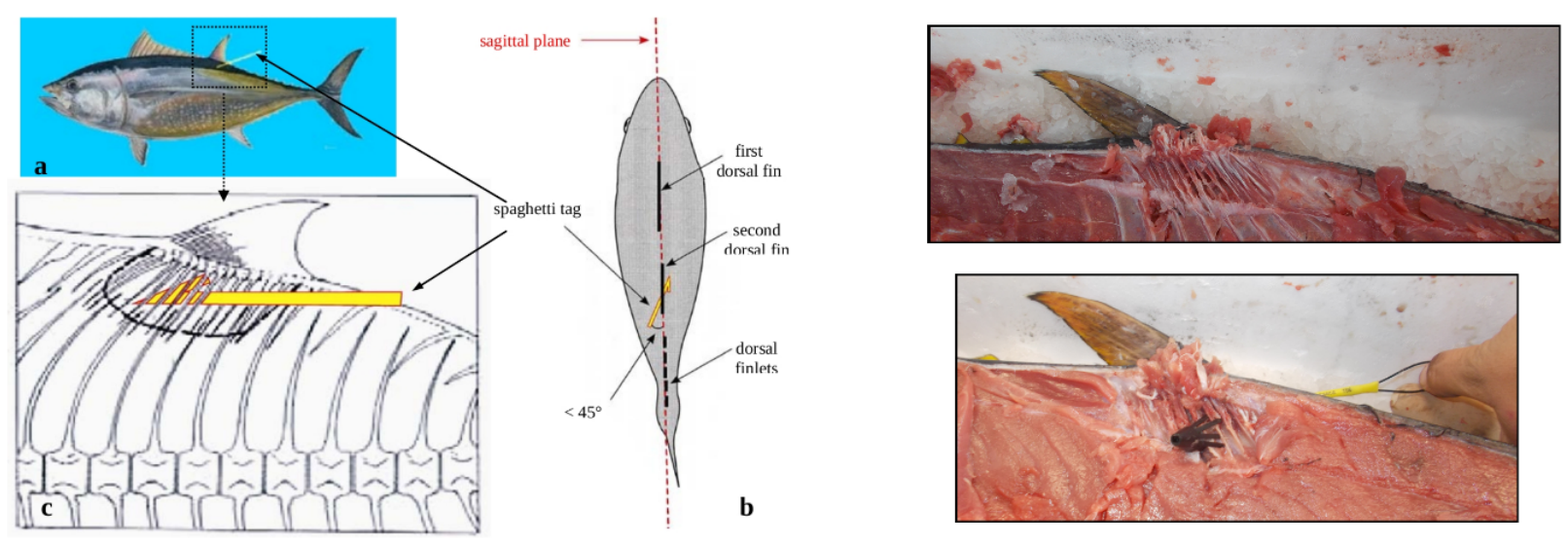

259 Figure 1: Implantation of the tag. The left panels (adapted from Cort et al., 2010) show the 260 insertion of the tags within the pterygiophores of the second dorsal fin. The top right panel 261 shows the pterygiophores of the second dorsal fin from an ABFT. The bottom right panel shows 262 a domeier anchor tangled within the pterygiophores. 

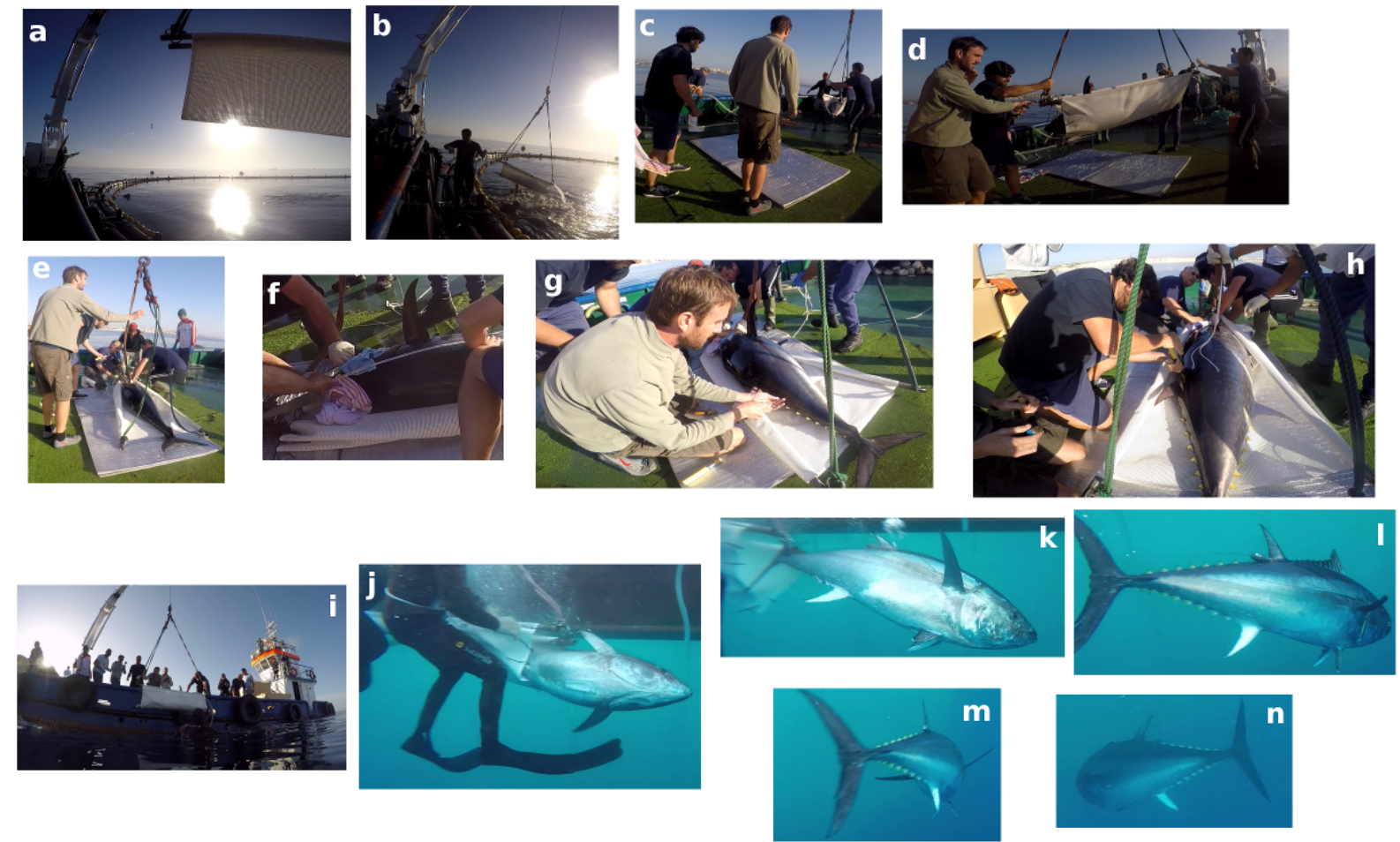

265 Figure 2: Tagging operation. The fish is hooked (a) and placed into a stretcher attached to a 266 crane (b). The tuna is placed onto a mattress with care (c-e). The stretcher is opened, the eyes 267 of the tuna are covered and a water pipe is placed in its mouth, while the hook is removed (f). 268 The tag is deployed on the fish ( $\mathrm{g}$ and $\mathrm{h}$ ). The stretcher is hauled back into the water (i) and the 269 fish returns in open waters $(j-n)$. 

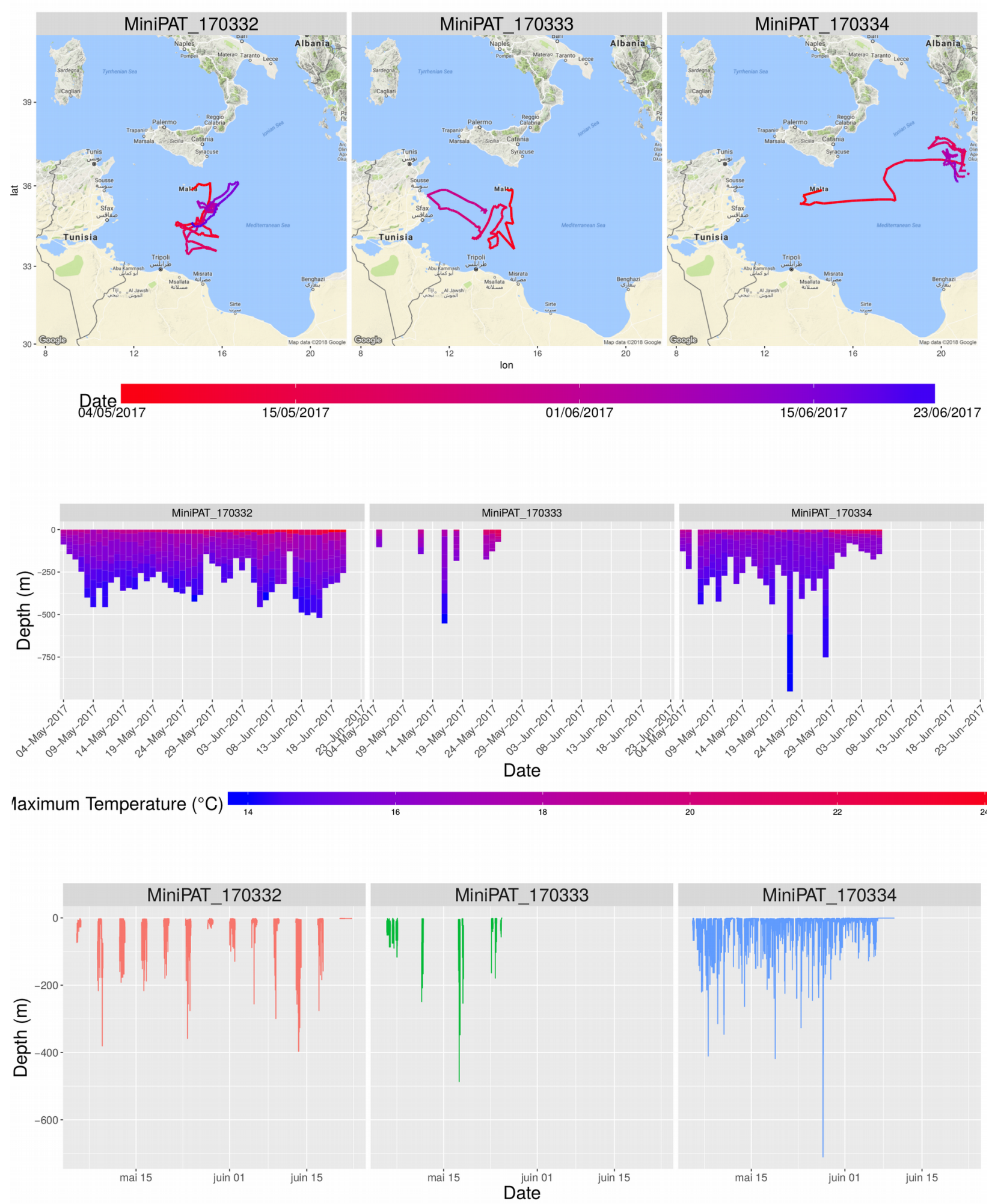
272 Figure 3: Data collected from the three tags deployed and geolocation processing results. The 273 top panel depicts the tracks of the fish obtained using the GPE3 state-space model algorithm 274 from Wildlife Computers, the second panel represents the temperature profile along the deepest 275 dive for each day and the third panel represents the diving pattern. For tag 170332 and 170333, 276 depth data were not collected every day. 